HEFAT2011

$8^{\text {th }}$ International Conference on Heat Transfer, Fluid Mechanics and Thermodynamics

11 - 13 July 2011

Pointe Aux Piments, Mauritius

\title{
SYNTHESIS AND OPTIMIZATION OF COOLING WATER SYSTEMS WITH MULTIPLE COOLING TOWERS
}

\author{
${ }^{1}$ Gololo K.V. ${ }^{1}$ Majozi T.* and ${ }^{2}$ Toshko Zhelev \\ *Author for correspondence \\ ${ }^{1}$ Department of Chemical Engineering, \\ University of Pretoria, \\ Pretoria, 0002, \\ South Africa, \\ ${ }^{2}$ Department of Chemical and Environmental Science, \\ University of Limerick, \\ Ireland
}

E-mail: thoko.majozi@up.ac.za

\begin{abstract}
Cooling water systems are generally designed with a set of heat exchangers arranged in parallel. This arrangement results in higher cooling water flowrate and low cooling water return temperature thus reducing cooling tower efficiency. Previous research on cooling water systems has focused mainly on heat exchanger network thus excluding the interaction between heat exchanger network and the cooling towers. This paper presents a technique for synthesis and optimization of cooling water systems which incorporates the performances of the cooling towers involved. The study focuses mainly on cooling systems consisting of multiple cooling towers that supply a common set of heat exchangers. The heat exchanger network is synthesized using the mathematical optimization technique. This technique is based on superstructure in which all opportunities for cooling water reuse are explored. The cooling tower model is used to predict the thermal performance of the cooling towers. Two case studies are presented to illustrate the performance of the proposed technique. The first case results in nonlinear programming (NLP) formulation and the second case yields mixed integer nonlinear programming (MINLP) problem. In both cases the cooling towers operating capacity is debottlenecked without compromising the heat duties of the associated heat exchangers [1].
\end{abstract}

\section{INTRODUCTION}

Industrial development and other economic activities have led to an increase in freshwater consumption and contamination of freshwater resources. One of the major water using operations in industries is the cooling water system. Cooling water systems use equipment such as cooling towers to remove waste heat from the process to the atmosphere. These systems also generate wastewater through the blowdown mechanisms.
Previous research on cooling water systems has focused mainly on debottlenecking the cooling towers through synthesis and optimization of the cooling water networks. The common technique used in this regard was based on graphical analysis approach [2-4]. This technique was derived from the principles of pinch analysis developed for heat exchanger networks synthesis by Linnhoff and coworkers [5-8]. The principles of pinch analysis were also adapted for mass exchange network synthesis [9] and later applied for targeting and synthesis of wastewater minimization problems [10]. Few authors used the superstructure based modelling techniques to optimize the cooling water systems [11-13]. Besides the application of this technique for cooling water systems optimization, it was also used by Takama et al. [14], Gunaratnma et al. [15] and AlvaArgáez et al. [16] for optimization of various water using systems.

The synthesis of cooling water systems which takes into consideration the interaction between cooling water networks and the cooling towers has not been fully explored. This paper presents a technique for synthesis and optimization of cooling water systems which incorporates the performances of the cooling towers involved. The study focuses mainly on cooling systems consisting of multiple cooling towers that supply a common set of heat exchangers. The heat exchanger network is synthesized using the mathematical optimization technique. The cooling tower model is used to predict the thermal performance of the cooling towers whilst taking the thermal conditions of the associated heat exchanger network into account. 


\section{NOMENCLATURE}

\begin{tabular}{|c|c|c|}
\hline$a, a_{f i}$ & $\mathrm{~m}^{2} / \mathrm{m}^{3}$ & Surface area per unit volume \\
\hline$A_{f r}$ & $\mathrm{~m}^{2}$ & Frontal area \\
\hline$B$ & $\mathrm{~kg} / \mathrm{s}$ & Cooling tower blowdown \\
\hline$C R$ & $\mathrm{~kg} / \mathrm{s}$ & Cooling tower return flowrate \\
\hline$C S$ & $\mathrm{~kg} / \mathrm{s}$ & Cooling water supply from any cooling tower \\
\hline$c_{p}$ & $\mathrm{~J} /\left(\mathrm{kg} .{ }^{\circ} \mathrm{C}\right)$ & Specific heat capacity \\
\hline E & $\mathrm{kg} / \mathrm{s}$ & Cooling tower evaporation \\
\hline$F$ & $\mathrm{~kg} / \mathrm{s}$ & Flowrate \\
\hline$F R$ & $\mathrm{~kg} / \mathrm{s}$ & $\begin{array}{l}\text { Reuse water from any cooling water using } \\
\text { operation }\end{array}$ \\
\hline$H_{a}$ & $\mathrm{~J} / \mathrm{kg}$ & Enthalpy of dry air \\
\hline$H_{m a}$ & $\mathrm{~J} / \mathrm{kg}$ & Enthalpy of moist air \\
\hline $\begin{array}{l}H_{v} \\
K\end{array}$ & $\mathrm{~J} / \mathrm{kg}$ & Enthalpy of vapour \\
\hline$K_{a}$ & $\mathrm{~kg} /\left(\mathrm{m}^{2} . \mathrm{s}\right)$ & Mass transfer coefficient \\
\hline$L e_{f}$ & & Lewis factor \\
\hline$m_{a}$ & $\mathrm{~kg} / \mathrm{s}$ & Dry air flowrate \\
\hline$m_{w}$ & $\mathrm{~kg} / \mathrm{s}$ & Water flowrate \\
\hline$O S$ & $\mathrm{~kg} / \mathrm{s}$ & Cooling tower outlet flowrate \\
\hline$Q$ & $\mathrm{~kW}$ & Duty of cooling water using operation \\
\hline$\widetilde{T}_{a}$ & $\mathrm{~K}$ & Air temperature \\
\hline$T_{w}$ & $\mathrm{~K}$ & Water temperature \\
\hline$w$ & $\mathrm{~kg} / \mathrm{kg}$ & Humidity of air \\
\hline$w_{s}$ & $\mathrm{~kg} / \mathrm{kg}$ & Humidity of saturated air \\
\hline$z$ & $\mathrm{~m}$ & Cooling tower height \\
\hline$i$ & index & Operation \\
\hline$n$ & index & Cooling tower \\
\hline
\end{tabular}

\section{COOLING WATER SYSTEM MODEL DEVELOPMENT}

The cooling water system consists of cooling towers and heat exchanger network. Therefore the mathematical model for designing cooling system entails the heat exchanger network model and the cooling tower model. The heat exchanger model entails a superstructure in which all possible cooling water reuse opportunities are explored. The mathematical formulation was developed from the superstructure given in Figure 2 by considering energy and mass balance equations across each cooling water using operation and at each node. The optimum heat exchanger network design is found by minimizing the cooling tower inlet flowrates. The interaction between the heat exchanger network and the cooling towers is investigated using the cooling tower model derived by Kröger [17].

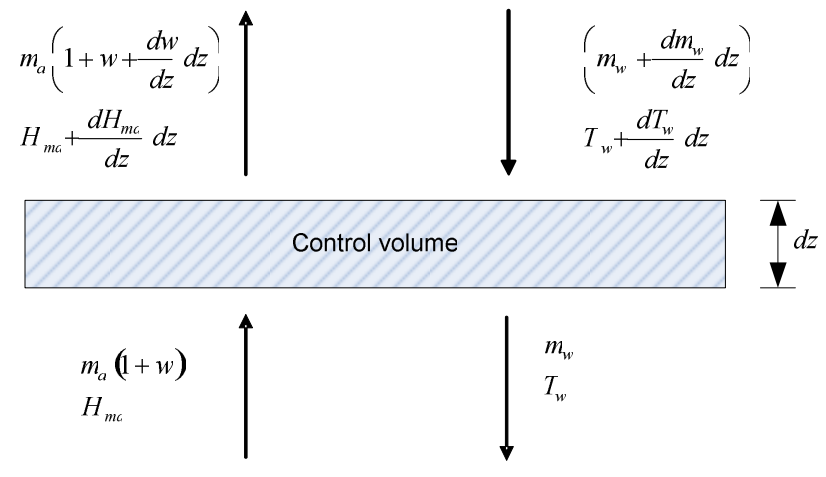

Figure 1 Control volume

The governing equations that predict the thermal performance of a cooling tower are given by Equations (1), (2) and (3) which were derived from the control volume shown in Figure 1. Equations (1) and (2) define the mass and energy balance for the control volume, respectively. Equation (3) defines the air enthalpy change for the control volume.

$$
\begin{aligned}
& \frac{d m_{w}}{d z}=m_{a} \frac{d w}{d z} \\
& \frac{d T_{w}}{d z}=\frac{m_{a}}{c p_{w} m_{w}}\left(\frac{1}{c p_{w}} \frac{d H_{a}}{d z}-T_{w} \frac{d w}{d z}\right)
\end{aligned}
$$

$$
\frac{d H_{a}}{d z}=\frac{K a_{f i} A_{f i}}{m_{a}}\left(L e_{f}\left(H_{a s}-H_{a}\right)+\left(1-L e_{f}\right) H_{v}\left(w_{s}-w\right)\right)(3)
$$

The heat exchanger network model is based on the following two possible practical cases.

Case I. Specified maximum cooling water return temperature to the cooling tower without a dedicated source or sink for any cooling water using operation. This situation arises when packing material inside the cooling tower is sensitive to temperature. Some packing materials undergo increased fouling at higher temperature. In this case any cooling tower can supply any water using operation whilst the water using operation can return to any cooling tower.

Case II. Specified maximum cooling water return temperature to the cooling tower with a dedicated source or sink for any cooling water using operation. This is similar to Case I except that the geographic constraints are taken into account. A particular cooling tower can only supply a particular set of heat exchangers and these heat exchangers can only return water to the same supplier.

Equation (4) and (5) are the mass balance constraints for the cooling towers and heat exchangers respectively. 


$$
\begin{aligned}
& O S(n)=\sum_{i \in I} C R(i, n)-B(n)-E(n) \\
& F_{\text {out }}(i)=\sum_{i \in I} C R(i, n)+\sum_{i^{\prime} \in I} F R\left(i, i^{\prime}\right)
\end{aligned}
$$

Equation (6) is the energy balance constraint for any heat exchanger.

$$
\left(T_{\text {out }}(i)-T_{\text {in }}(i)\right) F_{\text {in }}(i) c_{p}=Q(i)
$$

The energy balance for all streams supplying any operation yields Equation (7), which is the definition of inlet temperature into any cooling water using operation.

$T_{\text {in }}(i)=\frac{\sum_{i^{\prime} \in I} F R\left(i, i^{\prime}\right) T_{\text {out }}\left(i^{\prime}\right)+\sum_{n \in N} C S(n, i) T(n)}{F_{\text {in }}(i)}$

By substituting Equation (7) into Equation (6), the bilinear term $F_{\text {in }}(i) T_{\text {in }}(i)$ can be eliminated and Equation (6) and Equation (7) are replaced by Equation (8).

$Q(i)+c_{p} \sum_{n \in N} C S(n, i) T(n)+c_{p} \sum_{i^{\prime} \in I} F R\left(i^{\prime}, i\right) T_{\text {out }}\left(i^{\prime}\right)$

$=F_{\text {in }}(i) c_{p} T_{\text {out }}(i)$

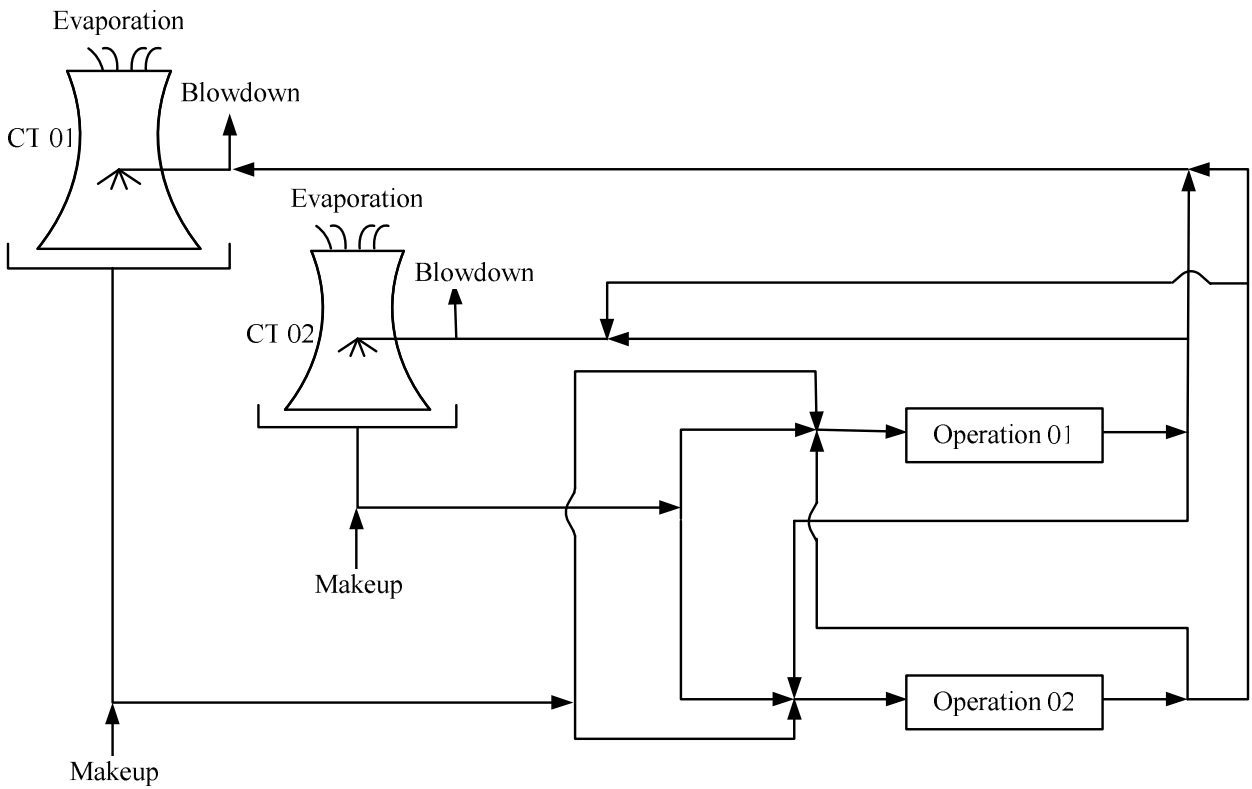

Figure 2 Superstructure for a cooling water system

\section{Reformulation linearization technique}

The technique starts by assigning a variable to each bilinear term e.g. $f n t(i)=F_{\text {in }}(i) T_{\text {out }}(i)$. The upper and the lower
The formulation for both Case I and II entails Equation (4)(8) that consist of bilinear terms which are nonconvex thus rendering the model NLP. However, Case II requires prevention of pre-mixing and post-mixing of cooling water from/to any cooling tower. Equation (9) and (10) prevent premixing of water from various cooling towers. Equation (9) ensures that the supply flowrate from any cooling tower to any operation cannot exceed the maximum allowable flowrate through the operation. Equation (10) ensures that any cooling water using operation can only be supplied by a maximum of one cooling tower. Consequently, the formulation for Case II consists of binary variables and bilinear terms. This renders the model mixed integer nonlinear programming (MINLP).

$C R(i, n) \leq F_{\text {in }}^{u}(i) y r(i, n)$

$\sum_{n \in N} y r(i, n) \leq 1$

where $y r(i, n)$ is a binary variable.

NLP model are difficult to initialize because the starting point might be infeasible or the solution might be locally optimum [17]. To overcome these difficulties the reformulation linearization technique proposed by Quesada and Grossmann [18] was used to linearize the bilinear terms. This technique uses the upper and the lower bounds to create a convex space for the bilinear terms. 
was also assigned a value. The bilinear term $F_{\text {in }}(i) T_{\text {out }}(i)$ can now be defined by Equation (11)-(14).

$$
\begin{aligned}
& f n t(i) \geq F_{\text {in }}^{u}(i) T_{\text {out }}(i)+F_{\text {in }}(i) T_{\text {out }}^{u}(i)-F_{\text {in }}^{u}(i) T_{\text {out }}^{u}(i) \\
& f n t(i) \geq F_{\text {in }}(i) T_{\text {out }}^{L}(i) \\
& f n t(i) \leq F_{\text {in }}^{u}(i) T_{\text {out }}(i)+F_{\text {in }}(i) T_{\text {out }}^{L}(i)-F_{\text {in }}^{u}(i) T_{\text {out }}^{L}(i) \\
& f n t(i) \leq F_{\text {in }}(i) T_{\text {out }}^{u}(i)
\end{aligned}
$$

Similarly, all other bilinear terms can be linearized as shown above. Introduction of linearization variables require Equation (8) to be modified as shown in Equation (15). The replacement of bilinear terms result in a relaxed LP model for Case I and MILP model for Case II.

$$
Q(i)+c_{p} \sum_{n \in N} t c s(n, i)+c_{p} \sum_{i^{\prime} \in I} \operatorname{frt}\left(i^{\prime}, i\right)=f n t(i) c_{p}
$$

where $\operatorname{frt}\left(i^{\prime}, i\right)=F R\left(i^{\prime}, i\right) T_{\text {out }}(i)$ and $\operatorname{tcs}(n, i)=C S(n, i) T_{s}(n)$

To obtain the solution for Case 1 and II, the relaxed model (LP/MILP) is first solved by minimizing the total recirculation cooling water. The solution of the relaxed model is then used as a starting point for solving the exact model (NLP/MINLP).

\section{Solution algorithm for combined cooling tower model} and heat exchanger network model.

The solution procedure can be applied for both cases considered. The first step is to optimize the heat exchanger network model without the cooling towers. The results from the first iteration, which are cooling water return (CWR) temperatures and flowrates, become the input to the cooling tower models. Each cooling tower model then predicts the outlet water temperatures and flowrates. This is done by first assuming the outlet water temperature of a cooling tower.The assumption is done by subtracting $0.5^{\circ} \mathrm{C}$ from the given cooling tower inlet temperature. The three governing mass and heat transfer equations, i.e. Equation (1), (2) and (3) are then solved numerically using forth order Runge_Kutta method starting from the bottom of the cooling tower moving upwards at stepsize $\Delta z$. When the maximum height is reached, the temperature at this point will be compared with the CWR temperature. If the two agree within a specified tolerance, the cooling tower model will stop and the outlet temperature will be given as the assumed temperature, else the inlet temperature will be adjusted until the CWR temperature agrees with the calculated temperature.

The predicted outlet cooling tower temperatures and flowrates then become the input to the heat exchanger network model. If the outlet temperature of the cooling tower model agrees with the previous inlet temperature to the heat exchanger network model, the algorithm stops which implies that final results have been obtained. Otherwise the iteration continues. The solution algorithm flowchart is shown in Figure 3. 


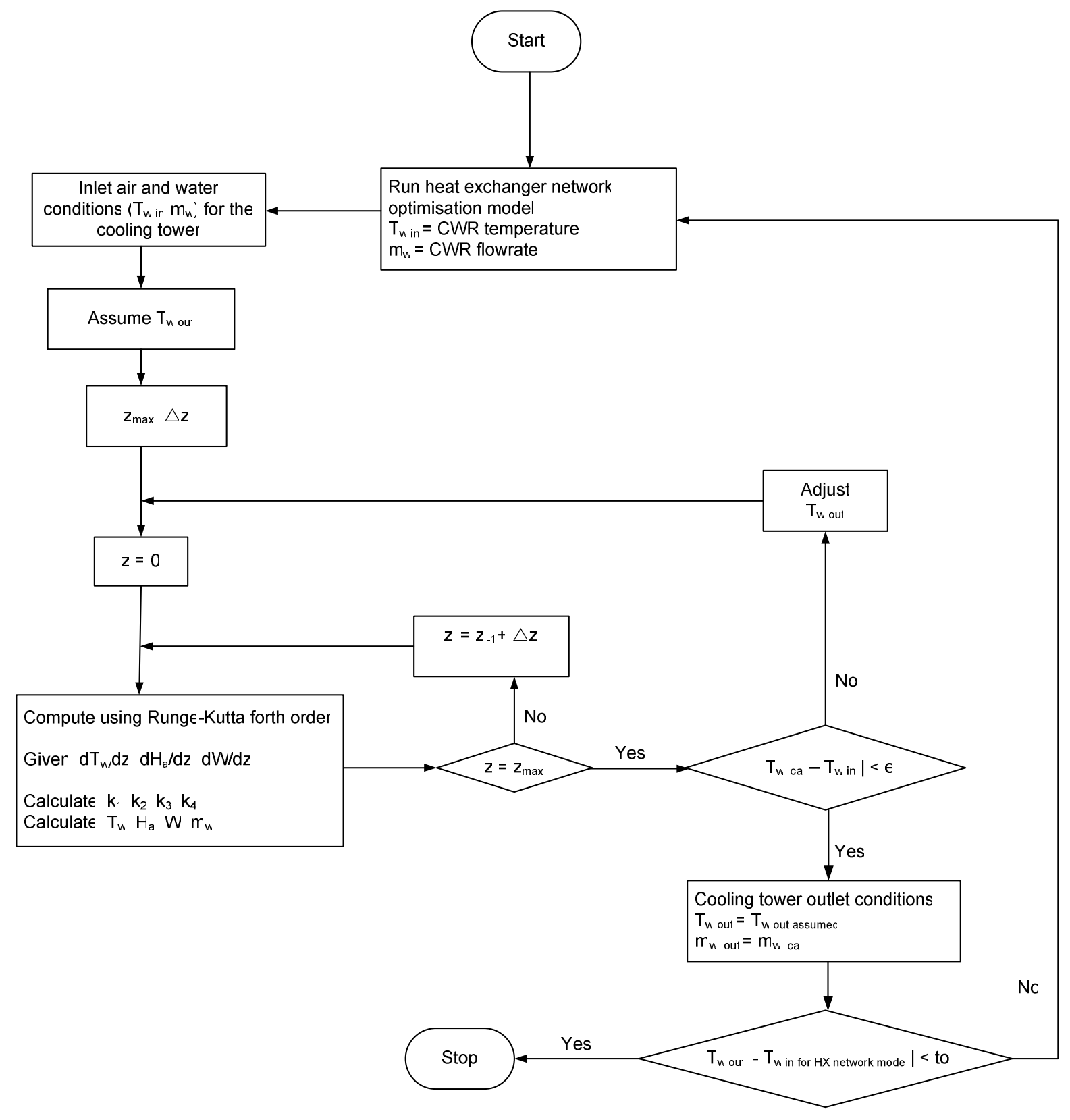

Figure 3 Flowchart for cooling water system model

\section{CASE STUDIES}

The application of the proposed technique is demonstrated by considering one example for Cases I and II. This example was extracted from the paper by Majozi and Moodley [10].

\section{Base case}

Cooling water system in Figure 4 shows a set of heat exchanger networks which are supplied by a set of cooling towers. Each cooling water using operation is supplied by freshwater from the cooling tower and return back to the cooling tower. The implication of these arrangements results in higher return cooling water flowrate and low return cooling water temperature thus reducing cooling tower efficiency [19]. 


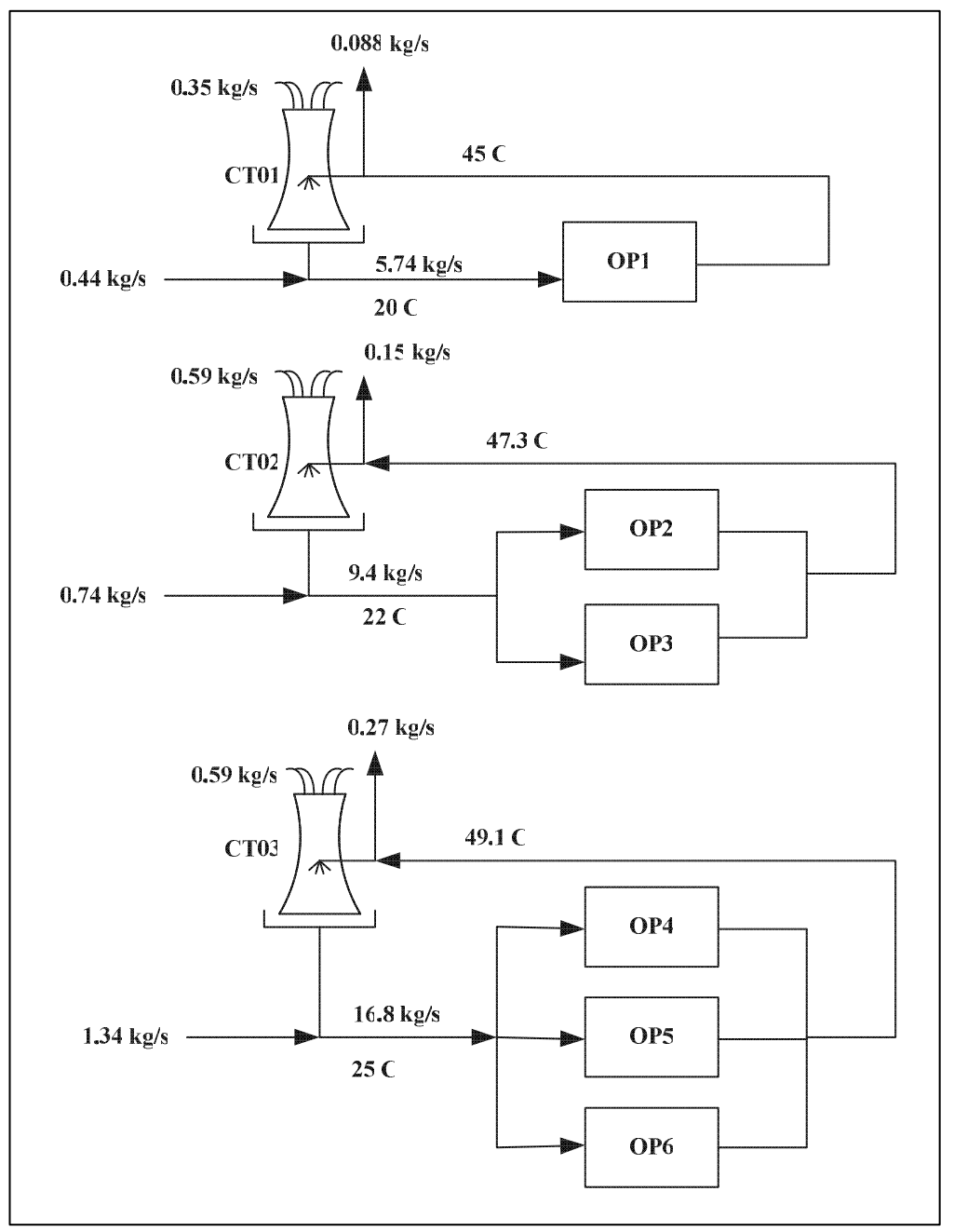

Figure 4 Base case (Majozi and Moodley, 2008)

\section{Case I}

In this case each cooling tower can supply any cooling water using operation. The return streams from any cooling water using operation can go to any cooling tower. The return temperature to any cooling tower is however specified.

Figure 5 shows the heat exchanger network after applying the methodology described above. By exploiting the opportunity for cooling water reuse, the overall circulating water decreased by $22 \%$ and one cooling tower was eliminated. The cooling tower inlet temperatures are at their maximum values.

These results show the opportunity to increase the heat duties, through expansions, without investing on a new cooling tower. The only additional investment required is on piping for reuse streams. Consequently, a detailed cost analysis would have to be conducted before implementation of these results. For this case study the makeup and the blowdown was also decreased by $7 \%$. However the decrease in makeup and blowdown cannot be guaranteed for all practical case studies and this is not the intended purpose in this study. The results summary is shown in Table 1.

\begin{tabular}{lll}
\hline Stream & Base case $(\mathbf{k g} / \mathbf{s})$ & Results $(\mathbf{k g} / \mathbf{s})$ \\
\hline Makeup & 2.52 & 2.33 \\
Blowdown & 0.50 & 0.47 \\
Circulating water & 31.94 & 24.80 \\
\hline
\end{tabular}

Table 1 Results summary 


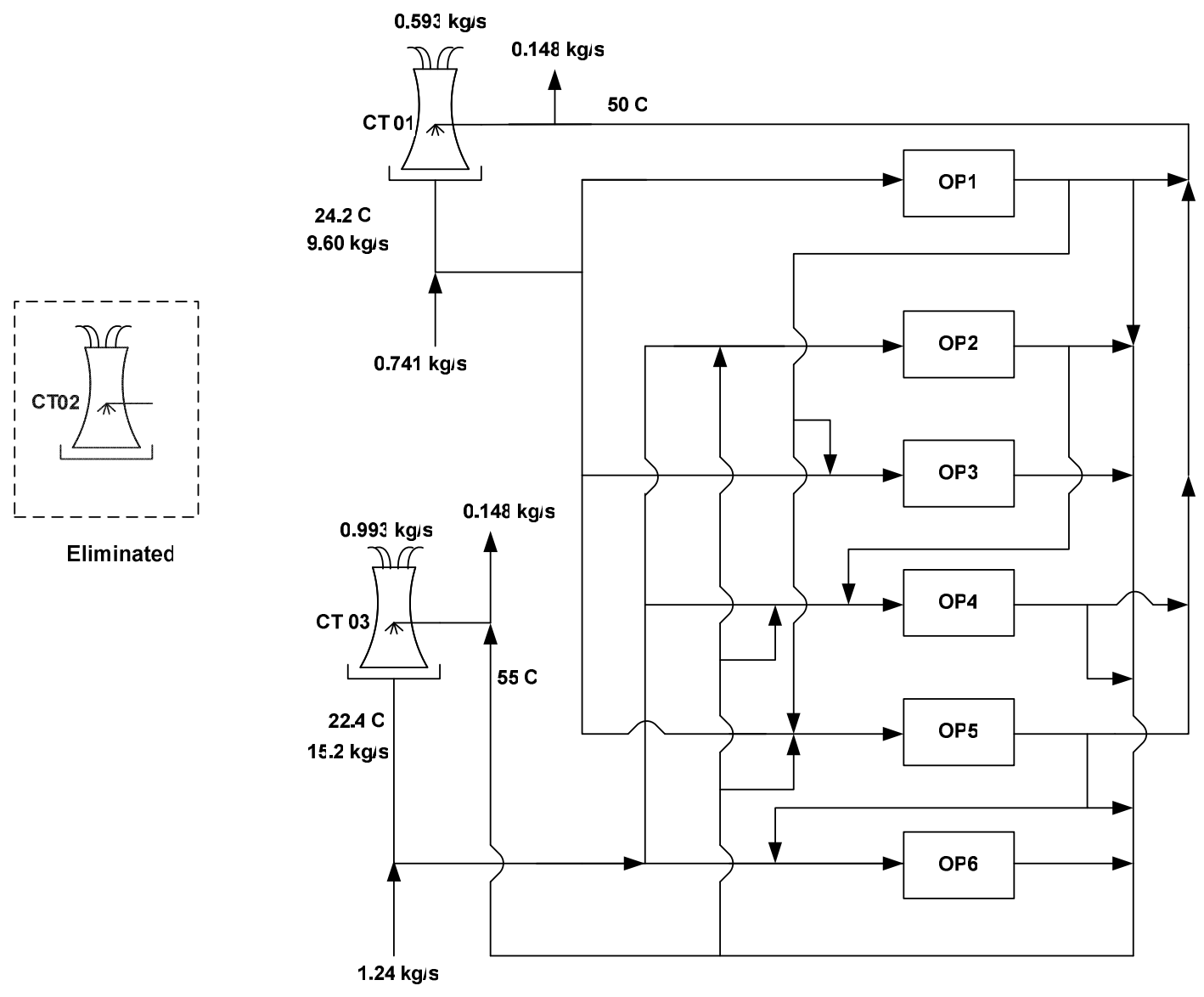

Figure 5 Final design of the cooling water system: Case I

\section{Case II}

In this case a cooling tower can only supply a dedicated set of heat exchangers. This implies that each operation can only be supplied by one cooling tower. The return streams from any cooling water using operation can only go to its supplier cooling tower. The return temperatures to the cooling towers are also specified. Figure 6 shows the heat exchanger network after applying the methodology described above.

By allowing for the cooling water reuse, the overall circulating water decreased by $20 \%$ as shown in Table 2 . This will decrease the pumping power requirement for the circulating pump thus reducing the pumping cost. The cooling towers spare capacity is also increased giving opportunities for increased heat load without investing in a new cooling tower. To satisfy the required heat duties with the reduced flowrate, the return temperature to the cooling towers is increased to the maximum value. The makeup and the blowdown are also decreased by $4 \%$. As abovementioned, the decrease in makeup and blowdown cannot be guaranteed for all practical case studies.

\begin{tabular}{lll}
\hline Stream & Base case(kg/s) & Results(kg/s) \\
\hline Makeup & 2.52 & 2.41 \\
Blowdown & 0.50 & 0.48 \\
Circulating water & 31.94 & 25.69 \\
\hline
\end{tabular}

Table 2 Results summary 


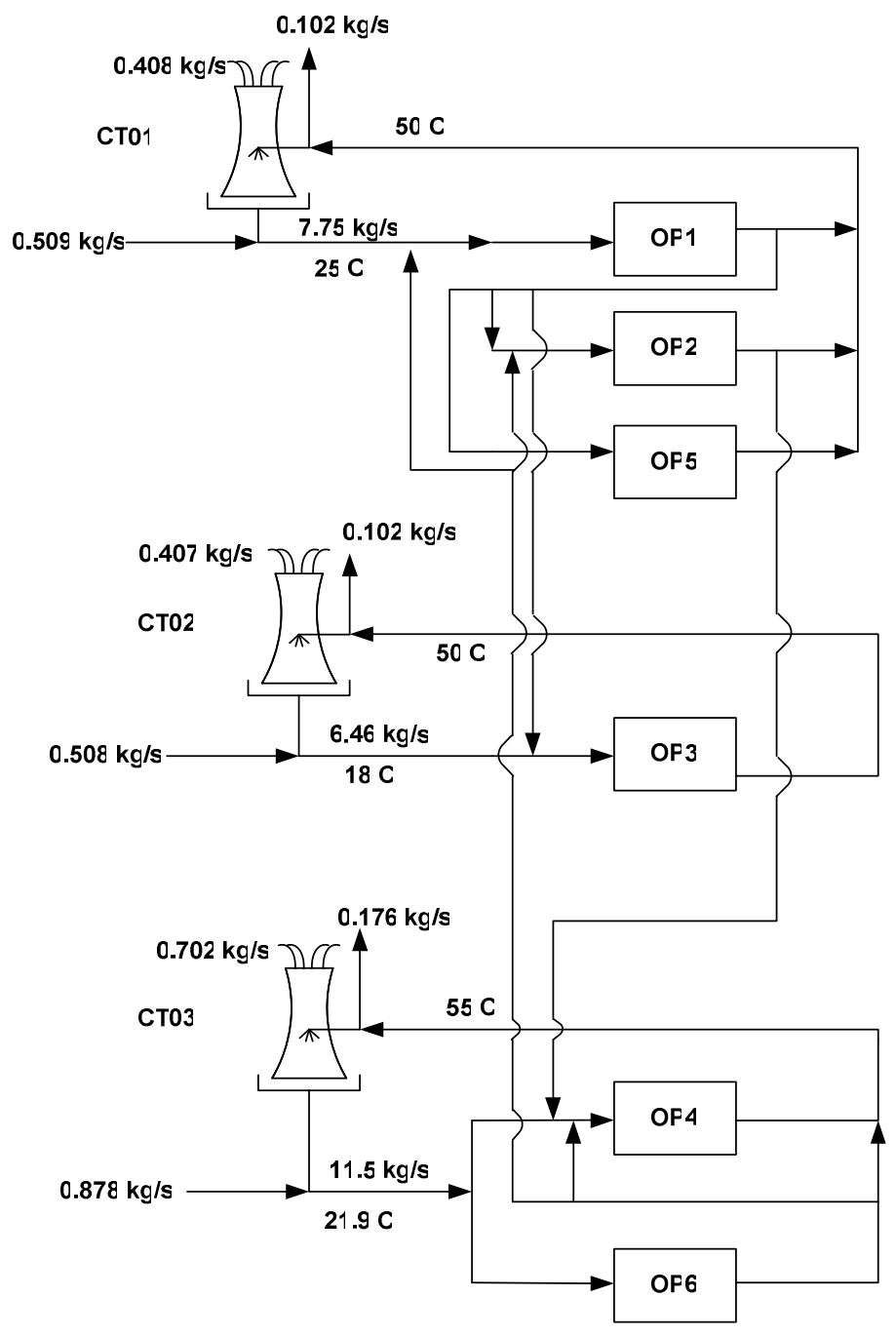

Figure 6 Final design of the cooling water system: Case II

\section{CONCLUSION}

The mathematical technique for cooling water system synthesis with multiple cooling towers has been presented. This technique is more holistic because it caters for the effect of cooling tower performance on heat exchanger network. The cooling tower thermal performance is predicted using the mathematical model. The results obtained using this technique are more practical, since all components of the cooling water system are included in the analysis.

The proposed technique has the advantage of debottlenecking the cooling towers, which implies that a given set of cooling towers can manage an increased heat load. Furthermore, the overall circulation water is also decreased with an added benefit of decreasing the overall power consumption of the circulating pumps. The overall cooling towers effectiveness was also improved. There is also a potential for the reduction of makeup and blowdown water flowrate. The proposed technique shows a potential for capital cost saving in grassroots and retrofit designs.

\section{REFERENCES}

[1] Gololo K.V., and Majozi T. On synthesis and optimization of cooling water systems with multiple cooling towers. Paper submitted to Industrial and Engineering Chemistry Research Journal, 2010.

[2] Kim J.K.and Smith R. Cooling water system design, Chemical Engineering. Science, Vol. 56, 2001, pp. 36413658.

[3] Kim J.K., Lee G.C., Zhu X.X.and Smith R. Cooling system design, Heat Transfer Engineering, Vol. 23. No. 6, 2002, pp. 49-61.

[4] Panjeshahi M.H., Ataei A., Gharaie, M. and Parand, R. Optimum design of cooling water systems for energy and water conservation, Chemical Engineering. Research and Design, Vol. 87, 2009, pp. 200-209.

[5] Linnhoff B. and Flower J.R. Synthesis of heat exchanger networks, AIChE Journal, Vol. 24, No. 4, 1978, pp. 633-642. 
[6] Linnhoff B. David R.M. and Wardle, I. Understanding heat exchanger networks., Computer and Chemical Engineering, Vol. 3 , 1979, pp. 295-302.

[7] Flower J.R. and Linnhoff B.A. Thermodynamiccombinatorial approach to the design of optimum heat exchanger networks, AIChE Journal, Vol 26, No. 1, 1980, pp. $1-9$.

[8] Linnhoff B. and Hindmarsh E. The pinch design method for heat exchanger networks, Chemical Engineering Science, Vol. 38, No. 5, 1983, 745-763.

[9] El-Halwagi M.M. and Manousiouthakis V. Synthesis of mass-exchanger networks, AIChE. Science, Vol. 8, 1989, pp. 1233-1244.

[10] Wang Y.P. and Smith R. Wastewater minimization, Chemical Engineering Science, Vol. 49, No. 7, 1994, pp. 981-1006.

[11] Majozi T. and Moodley A. Simultaneous targeting and design for cooling water systems with multiple cooling water supplies, Computer and Chemical Engineering, Vol. 32, 2008, pp. 540-551.

[12] Kim J.K.and Smith R. Automated retrofit design of cooling water systems, AIChE Journal, Vol. 49, No. 7, 2003, pp. 1712-1730.

[13] Ponce-Ortega J.M., Serna-González M. and JiménezGutiérrez A. Optimization model for re-circulating cooling water systems, Computer and Chemical Engineering, Vol. 34, 2009, pp. 177-195.

[14] Takama N., Kuriyama T., Shiroko K. and Umeda T. Optimal water allocation in a petroleum refinery, Computer and Chemical Engineering, Vol. 4, 1980, pp. 251258.

[15] Gunaratnam M., Alva-Argáez A., Kokossis A.C., Kim J.K. and Smith R. Automated design of total water systems, Industrial Engineering and Chemistry Research, Vol. 44, 2005, pp. 588-599.

[16] Alva-Argáez A., Kokossis A.C. and Smith R. Wastewater minimisation of industrial systems using an integrated approach, Computer and Chemistry Engineering, Vol. 22, 1998,pp. 741-744.

[17] Kröger D.G., 2004, Air-Cooled Heat Exchangers and Cooling Towers: Mass Transfer and Evaporative Cooling. Penn Well Corporation, USA.

[18] Quesada I. and Grossmann I.E. Global optimization of bilinear process networks with multicomponent flows, Computer and Chemical Engineering, Vol. 19, No. 12, 1995, pp. 1219-1242.

[19] Bernier, M.A. Cooling tower performance: Theory and experiments. ASHRAE Transactions Research, Vol. 100, 1994, pp. 114-121. 